\title{
IDEOLOGIA HEGEMÔNICA E CONTRA HEGEMONIA GRAMSCIANA: UMA PERSPECTIVA FILOSÓFICA
}

\author{
Hegemonic ideology and against gramscian hegemony: a philosophical perspective
}

Rosivaldo dos Santos Souza

RESUMO: Este trabalho de pesquisa visa discorrer sobre o conceito filosófico gramsciano de ideologia hegemônica e contra hegemonia, além de fornecer descrições de ideologia em Karl Marx, de onde parte a visão de Antônio Gramsci sobre o conceito apontado e do escritor Michael Löwy. Além de apontar o Projeto de Lei No 867 de 2015 como instrumento comprobatório da existência permanente e legítima de mecanismos de conservação e transformação ideológicos. Os tópicos estão elaborados em torno de três eixos temáticos: Ideologia e Verdade; Ideologia Hegemônica e Contra Hegemonia Gramsciana; Criticidade e Autonomia Intelectiva. Alguns estudiosos da filosofia gramsciana compõem a minha fundamentação teórica para esta pesquisa, como Carlos Nelson Coutinho, Paulo Freire, Demerval Saviane e Michael Löwy. Outros autores serão também citados para firmar o propósito da pesquisa.

PALAVRAS-CHAVE: Gramsci; ideologia; Marx

ABSTRACT: This research aims at discussing the Gramscian philosophical concept of hegemonic ideology and against hegemony, as well as providing descriptions of ideology in Karl Marx, from which Antônio Gramsci's view of the concept and writer Michael Löwy starts. In addition to pointing out Bill No. 867 of 2015 as a proof of the permanent and legitimate existence of ideological conservation and transformation mechanisms. The topics are elaborated around three thematic axes: Ideology and Truth; Hegemonic Ideology and Gramscian Hegemony; Criticality and Intellective Autonomy. Some scholars of Gramsci's philosophy compose my theoretical foundation for this research, such as Carlos Nelson Coutinho, Paulo Freire, Demerval Saviane and Michael Löwy. Other authors will also be cited to state the purpose of the research.

KEYWORDS: Gramsci; ideology; Marx 


\section{INTRODUÇÃO}

A maneira como a realidade social é compreendida tem como fundamento um processo de consolidação de ideias postas como verdades e que perpassam pelo senso comum construindo um consenso hegemônico. Porém, apesar de ser coerente e coesa em sua estrutura, essa visão hegemônica de mundo possui lacunas em sua fibra que possibilitam a passagem de ideias contra hegemônicas.

Karl Marx vestiu o conceito de hegemonia com uma roupagem onde ela é representada como visão distorcida da realidade. Lênin, por sua vez, dotou o termo de um caráter positivo quando atrelou-o a uma classe social proletária que precisa montar sua identidade de classe com suas próprias mãos e com visão própria. Já Antônio Gramsci, afirmou ser a ideologia hegemônica a fundamentação legítima da sociedade. Aquilo que concede firmeza a conjuntura social sob o poder de uma determinada classe social que, para ele, luta contra aqueles que tentam minar sua autoridade e controle sociais por meios de ações contra hegemônicas.

\section{IDEOLOGIA E VERDADE}

O ser humano, com seu pensamento, com suas ações e sentimentos está vinculado à um repertório complexo de parâmetros ideológicos que firmam, justificam e dão sentido a existência. Os valores e princípios que orientam o pensar, o sentir e o agir são produtos da relação dialética entre a ideologia hegemônica e a contra hegemonia. A ideologia dominante detém o controle da práxis humana a tal ponto que pode levar aqueles que nela fundamentam sua vida à uma naturalização da vida social. Segundo (FREIRE, 2002), a ideologia possui poder para torna aquilo que é resultado da ação histórica em produto invariavelmente necessário.

As verdades nos cercam e nos fazem imagina-las como constituintes da realidade objetiva. Elas são tratadas com tanta naturalidade que acabam compondo nosso repertório de crenças de maneira necessária. As instituições mantenedoras dessas verdades se colocam não somente como suas promotoras, mas também como suas guardiãs e defensoras. Essas verdades, vistas em seu conjunto, são percebidas com tanta naturalidade e organicidade que acabam formando um quadro coeso e harmônico. Elas parecem que estão no lugar certo e que precisam permanecer como estão. Até parece que um ser fantástico as colocou lá para o bem de todos que as reconhece e reverenciam. Enquanto que aqueles que as negam e criticam são merecedores das correções e punições devidas. 
Muitos filósofos já se debruçaram sobre o tema da ideologia como conjunto de regras e normas que existem para dar solidez e harmonia à sociedade. Muitos deles inclusive salientam a importância dela para a manutenção da solidariedade orgânica dos agrupamentos humanos e para a manutenção dos pilares que levarão a raça humana à formas de vida cada vez mais pacíficas e fraternais.

Apesar dessas representações idealistas existirem em níveis robustos em muitos seguimentos sociais, elas se deparam frequentemente com situações que mostram o contrário. Os conflitos sociais, políticos, econômicos, religiosos e éticos-raciais, bradam com tanta eloquência e vivacidade que todos podem ouvir, ver e sentir seus efeitos. É praticamente impossível o desperdício e a fome, os casebres e as mansões, os salários dos operários e as grandes fortunas dos patrões, a miséria da palafita e a riqueza dos condomínios, passarem despercebidos. As percepções humanas não estão arrefecidas, pelo contrário, estão mais latentes e potencializadas com as novas tecnologias de informação e comunicação disponíveis. Os nossos sentidos estão intactos e saudáveis. Eles continuam recebendo as impressões do mundo externo como sempre receberam. Inclusive até nos questionamos diante de flagrantes inequívocos. Aliás, nos vemos partícipes dessa realidade contraditória. Porém, mesmo enxergando as disparidades sociais ao redor; sentindo na pele a dor da violência causada por esse estado de coisas; chorando com o próximo a infelicidade de ter que viver a falta e a escassez do que é básico para se manter vivo, quase são se escuta uma brado de revolta. Quase não se vê mãos erguidas e unidas exigindo reformulações na sociedade. E os poucos casos de insurreição quando ocorrem são tratados como rebeldias e desordens. E muitos daqueles que sofrem com as agruras da desigualdade ainda defendem a ordem das coisas pois entendem que a falta para alguns e a sobeja para outros é natural, comum, ordinário. A ideologia tem sim o poder de nos fazer dóceis e amáveis, mesmo perante situações controversas. Ela pode tornar a sociedade apática e acrítica diante das próprias calamidades sofridas. Ela ainda possui o poder de naturalizar os fatos sociais e torna-los necessários. A ideologia minimiza, obstrui e deprecia a capacidade humana de transformar e reconstruir sua própria realidade. Ela possui o poder de nos fazer enxergar o que não existe e de nos fazer cegos diante da realidade.

A estrutura ideológica que norteia a vida particular e social dos indivíduos apesar de se mostrar com uma aparelhagem hegemônica e naturalizadora da realidade histórica, não está de todo imune às críticas e ações contestatórias. Inclusive, a ideologia dominante, pode até assimilar partes substanciais de novas ideias que surgem, primeiramente conflitantes, porém, com o tempo, mostram-se adequadas e valiosas. Afinal de contas, as ideias são produto da interação humana com o outro. E esse outro não precisa ser necessariamente uma pessoa, mas a natureza exterior 
ao homem e até o próprio homem que se comunica consigo mesmo em ação reflexiva. Sendo assim, haverá sempre um interlocutor que, além de poder aceitar resolutamente um paradigma, uma ideologia, poderá também refuta-lo ou até amplia-lo ou reconstruí-lo sob orientação de nova percepção e perspectiva. A ideologia hegemônica ganha essa qualificação por que se tornou verdade justificada e foi aceita como padrão de comportamento e pensamento legítimo.

A ideologia teve como ponto de partida o pensamento do conde de Tracy, AntoineLouis-Claude Destutt, nascido em Paris da Revolução Francesa, foi influenciado por Condorcet e ocupou cadeira no Parlamento defendendo posicionamentos republicanos em oposição aos bonapartistas. Fundador da escola filosófica dos chamados ideólogos, trouxe ao público o pensamento de que as ideias são elementos naturais oriundas da relação do homem com a natureza. Por meio dessa Ciências das Ideias, o conde de Tracy propões uma explicação de como nascem as ideias na sociedade.

Muitos são os pensadores que se debruçaram sobre a corrente da filosofia que trata dos postulados da teoria do conhecimento. Alguns deles se propuseram a defender o argumento que afirma ser a ideia um elemento preexistente. Outros, pelo contrário, apontam que as ideias surgem a partir das percepções das coisas físicas existentes no exterior da consciência humana. Ainda existem aqueles que fundamentam sua fala sobre o pensamento de que as coisas físicas só existem quando estão em nossa consciência, passando a inexistência quando mudamos a atenção para outra coisa diferente.

Como é possível observar esse tema da verdade enquanto ideia ou conjunto de ideias que orientam ou devem orientar o comportamento individual e social das pessoas não é tão simples como aparenta ser. Muito se foi produzido sobre esse tema e ainda continua sendo. Então, o que vale para todos até aqui, pelo menos no plano consensual, crítico ou acrítico, é que a verdade existe, no mínimo em termos de fato, de veracidade, de juízo, de ilusão e de dogma.

Esse conjunto de ideias, que muitas vezes são aceitas como verdades, no pensamento de Karl Marx, não passa de uma ilusão que mascara a realidade da luta de classes e que tem a capacidade de conservar a exploração como elemento natural e inevitável.

Já para Gramsci, filósofo italiano da linhagem marxista, a ideologia é sim uma verdade que fornece solidez e estabilidade a uma forma de sociedade. Para ele, esse conjunto de ideias, irá criar um senso comum que firmará o que se vive como sendo próprio e justo, tornando a realidade uma verdade a ser seguida por todos. Essa ideologia, depois de ser aceita pelo consenso, será hegemônica e racional. Pelo menos até as novas ideias surgirem e adentrarem pelas fissuras do sistema. 


\section{IDEOLOGIA HEGEMÔNICA E CONTRA HEGEMONIA GRAMSCIANA}

Partindo dos postulados marxistas sobre a ordem da sociedade em torno de conflitos ou lutas de classes e da justificativa que legitima a realidade enquanto verdade a ser seguida por todos, proponho a ideologia hegemônica como conceito que significa, verdades absorvidas e aceitas pela sociedade, seja pelo crivo da crítica ou não, como parâmetro ideológico legítimo e digno de aceitação universal. Apesar de não estar imune à contraposições e críticas que surgem à medida que a verdade da classe dominante não atende aos interesses de todos irrestritamente e na medida em que a dinâmica da vida em sociedade elabora novas demandas ou resgata e conserva antigos valores.

Mas o conceito de ideologia não tem sua origem nas forjas marxistas. Esse termo foi cunhado dentro do processo revolucionário francês do século XVIII. Ele não nasce como produto do seu idealizador, mas como crítica do seu trabalho por parte de seus opositores bonapartistas. Insultados, os ideólogos acabaram recebendo essa alcunha daqueles que afirmavam que eles não pautavam suas reflexões no mundo real, mas no mundo nebuloso dos devaneios e das efêmeras ideias.

Para LÖWY (2015), o conde de Tracy, afirmava ter seu trabalho um aparato científico que analisava as ideias como resultados da interação entre "o organismo vivo e a natureza, o meio ambiente". Ou seja, para seu criador, a ideologia tinha mais haver como o materialismo do que com a metafísica, como alegou Napoleão Bonaparte.

Com o passar do tempo o termo ideologia passa a aglomerar e a representar novos conceitos. Em termos mais genéricos, ideologia significa, segundo (ABBAGNANO, 2007), uma "visão de mundo, de um grupo humano". Esse conceito então, diversamente da interpretação marxista tradicional, diz respeito somente, àquilo que está representado no cognitivo humano sobre a realidade vivida como ideia, ou conjunto de ideias, crenças, valores e normas, assumidas e entendidas como verdades justificadas. Mas ele não permanece acrítico como foi inicialmente posto.

Quando chegou ao repertório de reflexões de Karl Marx, esse conceito ganhou nova formulação e indumentária crítica e consubstancialmente dialética. Marx, entre outros pensadores do chamado grupo "da desconfiança", entendia que a ideologia era mecanismo psicológico e filosófico, enquanto visão de mundo, que camufla e cobre a realidade como ela é. Esse pensador muito importante para o entendimento dos fatos sociais dentro dum prisma dialético, inaugurou um jeito extremamente revolucionário para o entendimento da realidade humana. É com ele que 
esse conceito irá fundamentar as formulações teóricas de outros pensadores posteriores, tanto dos que lhe tem grande apreço, quanto dos que lhes tecem críticas.

Como bem salientou LÖWY (2015), a ideologia é formulação duma classe que pretende justificar o estado de coisas por meio de um itinerário reflexivo que falseia a realidade; que torna nebulosa a realidade; que forma o ideário pessoal e coletivo da sociedade a partir de formulações puramente intelectivas; que afirma ser o poder da classe hegemônica, legitima e comum; que diz ser a pobreza e a falta, condição própria e necessária, numa sociedade onde a diversidade étnica, cultural, biológica, política, econômica e social, são fatores inevitáveis.

Diferentemente de Marx, Lenin evoca o termo não de maneira negativa, como fez o criador do socialismo científico, mas de maneira que a torna uma concepção legítima da realidade, vinculada tanto a classe dominante quanto a classe dominada. Em Lenin a ideologia não está somente vinculada a classe hegemônica, mas possui também, relações com a classe proletária. Por que qualquer grupo humano específico, segundo Lenin, precisa justificar sua prática social e suas crenças legitimadas. Ele entendia que qualquer classe social possui interesses que lhes são próprias. E esses interesses demandam formulações teóricas que possam justificar crenças, valores e ações que, dentro de determinadas conjunturas, fazem sentido; e em outras, nem tanto.

Ainda segundo LÖWY (2015), Karl Mannheim, entende ideologia como conjunto de concepções que dão estabilidade social. Para ele, ideologia é representação cognitiva elaborada com o fim de justificar e conservar a ordem estabelecida. São postulados que cimentam, mesmo que inconscientemente, os indivíduos dentro de uma realidade colocada como verdade necessária.

Antônio Gramsci, um dos mais valorosos expoentes da corrente marxista renovada do século XX, retomando o conceito de ideologia a partir dos seus antecessores, coloca no termo uma caracterização muito mais abrangente e profunda. Ele afirma ser a ideologia resultado das transformação sociais e históricas. Entende ele que a ideologia não é um dogma intransponível e irreversível. Ele defende que a ideologia é fenômeno histórico e passível de mudança, de rompimento e de extinção. E isso, segundo LÖWY (2015), dentro do próprio postulado marxista.

Para Gramsci, o marxismo vai passar, como todas as ideologias. Para tanto, é necessário que aquilo que mantem de pé a ideologia hegemônica, deixe de existir. Quando a propriedade privada dos meios de produção deixarem de existir, também deixará de existir a ideologia marxista. Isso por que, dentro de uma ideologia majoritária e hegemônica, a ideologia marxista é contra hegemônica e assim sendo, aquilo que era puramente utopia, ou seja, pensamento visto 
como algo inviável em um dado momento histórico e que se propõe crítico daquilo que é hegemônico, deixará de sê-lo para passar a constituir aquela estrutura ideológica que antes a censurava. Segundo LÖWY (2015), essa visão de mundo torna o pensamento marxista gramsciano radical em sua própria formulação.

Dessa maneira a visão que se tem da realidade do mundo, na opinião de Gramsci, não é dogmática e muito menos intransponível e eterna em seu status quo. Ela, inevitavelmente, passa por inúmeras influências que a reformulam gerando o novo que, não precisando ser necessariamente o diferente ou o oposto, reconfigura-se diante dos novos determinantes e se mantem viva e atuante, mesmo que seja em conteúdo, formatação e temática diferentes.

Para Antônio Gramsci, a ideologia faz parte do arcabouço estruturador da sociedade. É aquele mecanismo que, se bem usado, diminui a necessária utilização das forças violentas e coercitivas do aparato estatal para impor a realidade. A ideologia, para Gramsci, é a maneira cordial e consensual de justificar e explicar a realidade como ela é. Em JONHSON (2008), a ideologia gramscista possui o poder construtor de consenso em torno de verdades que atendem a interesses de classe. Como foi mostrado anteriormente, o consenso em Gramsci não possui um sentido puramente abjeto. Aliás, o marxismo gramsciano entende que o consenso estabelecido na ideologia traz solidez para o grupo que o aceita.

É nesse encaminhamento que Gramsci afirma ser todo homem um filósofo. Para ele filosofia é uma maneira de ver o mundo, assim como também é a cultura, o folclore, a religião e a ciência. Ele entende que esses elementos são produções da infraestrutura e que estão sujeitos aos determinantes do processo histórico.

Antônio Gramsci não descarta o senso comum e muito menos o consenso como mecanismos estruturadores da sociedade. Esse senso comum para Gramsci, é a base onde serão montados todos os outros postulados que formarão a visão de mundo do indivíduo, mesmo que de maneira incoerente e desconexa com a realidade. Porém, com as trocas constantes com as ideias hegemônicas e com as reformulações que se farão do campo cultural, a ideologia contra hegemônica ganhará mais autonomia, avançando para noções mais claras da realidade e favorecendo a conscientização dos grupos minoritários.

Para Karl Marx, a consciência de classe é a plena compreensão da classe operária de sua condição. Para ele o operariado que não se enxerga como uma classe distinta do capital, mas que até defende e luta em favor dela, possui uma falsa consciência de classe. Marx explica esse fenômeno como resultado do falseamento da realidade por meio da ideologia que, segundo ele, impõe-se hegemonicamente sobre todos. Mas que, apesar disso, não consegui de todo mascarar 
suas naturais contradições. E diante dessas contradições, cada vez mais presentes na sociedade capitalista, o proletariado irá se insurgir.

Antônio Gramsci vê tudo isso de maneira mais proativa. Ele afirma que é necessário a organização de operários intelectivos do marxismo para poder orquestrar essa insatisfação quando ela ocorrer. Para tanto, a formação de um conjunto de intelectuais orgânicos, faz-se preciso.

Para Gramsci não se deve lutar apenas no plano da política e da economia. O plano intelectual é sumamente importante e indispensável para que o processo revolucionário tome dimensões grandiosas. Ele defende que a luta deva ser travada também no mundo intelectivo e cultural. Para o marxismo gramsciano o mundo cultural não deve ser desprezado como campo de batalha. Essa consciência de classe, tão desejada pelo marxismo tradicional, só irá se efetivar quando ocorrer um fortalecimento e uma ampliação dos chamados intelectuais orgânicos. Figuras que, para Gramsci, possuem valor significativo no processo tomada de consciência.

Seguindo os postulados de Antônio Gramsci, Paulo Freire entende que não se deve desconsiderar o conhecimento prévio que alunos trazem para a escola. Ele afirma que esse conhecimento, mesmo sendo do senso comum, é rico de coisas que fazem parte da realidade do educando e é a partir do que o aluno sabe da sua realidade que o professor irá trabalhar para desatualizá-la e possibilitar alguma mudança necessária. Não somente material, mas também cognitiva e psicológica. Segundo FREIRE (2011), o conhecimento prévio, que traz a visão de mundo que o aluno tem, é o ponto de partida para alçar novos voos, rumo à visões autônomas e críticas da realidade.

\section{CRITICIDADE E AUTONOMIA INTELECTIVA}

O pensamento filosófico nos alerta da necessária condução produzida pela ética da ideologia hegemônica. Não se pode descartar a real posição que todo ser humano está logo que começa a conhecer e a lidar com às várias possibilidades e opções colocadas pelo viver.

O termo heteronomia em ABBAGNANO (2007), está associado ao inverso de autonomia. Nicola Abbagnano deixa bem claro que esse conceito é a afirmação do desejo sobre a vontade. As paixões ganham volume tal no espírito humano que condiciona a razão e a coloca sob seu domínio e controle.

Além disso, o termo se refere a falta duma lei própria para guiar à vontade daquele ser racional e ético que, em todo momento precisa considerar a vida social como necessária e por isso deveria a si mesmo impor um princípio ou uma teoria que o oriente nos momentos decisórios da vida social e particular. 
A falta de autonomia me parece legítima nos primeiros momentos da vida. Essa legitimidade de que falo está muitíssimo ligada ao grau de dependência que existe entre os seres humanos na hora de manter a vida e suas capacidades e habilidades. Diferentemente dos outros seres não racionais, o ser humano precisa absolutamente dos cuidados de outro ser humano mais experiente para poder se manter como ser humano vivo e capaz de potencializar sua humanidade.

Dentro desse raciocínio podemos defender a heteronomia enquanto aspecto relevante na formação da humanidade. Pelo menos enquanto se constrói o homem autônomo e livre, não dos seus desejos, mas da dependência que marca os espíritos iniciantes no viver e também aqueles que são covardes e amedrontados diante das angustias da vida, além dos que, por qualquer transtorno psiquiátrico, precisam ser mantidos por mais tempo sob a tutela e dependência intelectiva e cognitiva de outro igual.

Não existe nenhum demérito na relação humana intermediada pela heteronomia. Pelo contrário, esse tipo de relação, como foi dito, é necessária e humanizadora. Mesmo sendo caracterizada pela condução e pela obediência um tanto impositiva, afinal de contas uma das partes assume a ação sem saber claramente o porquê dela.

Diante disso, a outra parte, aquela mais experiente e cônscia dos seus conhecimentos e práticas sociais já testadas e instituídas em seu código de valor, seguirá conduzindo e referendando o outro, a menos que entenda a autonomia como capacidade em si mesma necessária e de existência histórica, deliberada e pedagógica em todo ser racional e ético. Ou seja, não se nasce autônomo, ensina-se e aprende-se a autonomia. Ela é produto da ação humana e de suas relações de ensino aprendizagem. Manter o outro dependente e seguro nos princípios alheios é no mínimo antiético e desumano.

Gramsci atribui à escola um grande significado e importância por que é nela que muito pode ser feito na maturação da autonomia dos educandos. A escola pode ser canal que possibilite a construção da consciência de classe e a conseguinte emancipação cognitiva e cultural.

Apesar de ver na escola um ambiente marcado pela ação da ideologia hegemônica, Gramsci ver nesse espaço um local de confronto cultural dialético, capaz de fazer avançar o pensamento dos estudantes para níveis mais elevados de autoconsciência e formação emancipatória.

David Paul Ausubel, norte-americano psicólogo da educação, nascido na Nova York em 1918, entendia que aquilo que era ensinado ao aluno pela escola não surtia efeito positivo se fizesse parte de uma estrutura de ensino reacionária e impositiva. O processo de ensino aprendizagem para ganhar sentido e ter um grau mínimo de importância para o aluno deveria 
considerar o que ele já sabia. Fazer conexões arbitrárias entre o conteúdo que se ensina e a estrutura mental do aluno seria o mesmo que tentar misturar água e óleo.

A aprendizagem significativa de Ausubel salienta a importância em se considerar a estrutura cognitiva do aluno para que o novo apresentado ganhe significado e sentido para ele. Essa interação entre o conteúdo apresentado pelo professor e os conceitos prévios do aluno, segundo Ausubel, é de fundamental importância no processo de aprendizagem, do contrário, ocorrerá aquilo que Ausubel chama de aprendizagem mecânica. Esse tipo de aprendizagem só favorece a memorização de conceitos e fórmulas que, com o tempo, serão totalmente esquecidos por falta de uso, importância e significado.

Adriana Pelizzari, especialista em Processos Pedagógicos pela PUC Paraná, aponta no artigo intitulado "Teoria da Aprendizagem Significativa segundo Ausubel” que, existem duas condições necessárias para a efetivação da aprendizagem significativa. Uma delas diz respeito ao aluno apresentar disposição para aprender ou apenas memorizar fórmulas e conceitos; a segunda se refere ao conteúdo ser potencialmente significativo para o aluno.

É salientado por PELIZZARI (2002) que, quanto mais apta for a conexão entre o conteúdo e a estrutura prévia que o aluno apresenta, mais significativa será a aprendizagem; quanto mais distante o conteúdo estiver do aluno, mais mecânica será a aprendizagem. Dentro desse panorama, a aprendizagem por descoberta torna mais potente a aprendizagem significativa. Enquanto que a aprendizagem receptiva tende a fortalecer a aprendizagem repetitiva.

$\mathrm{Na}$ história da educação brasileira a filosofia figura em um plano um tanto intermitente, hora está presente como disciplina curricular obrigatória, hora como tema transversal e interdisciplinar. Esse tipo de ação sobre essa área do conhecimento tem uma explicação no plano dos interesses ideológicos.

Nas Orientações Curriculares para o Ensino Médio é colocado que a partir da lei $\mathrm{n}^{\circ}$ 4.024/61 e da lei 5.692/71, a filosofia é excluída do programa curricular obrigatório do ensino médio. Ela só retornará ao currículo como disciplina obrigatória com a lei no 9.394/96 que determina, como uma das suas atribuições, formar no aluno o conhecimento necessário para o devido exercício da cidadania. Porém, mesmo figurando entre as disciplinas obrigatórias, a filosofia é colocada na prática como tema transversal.

Esse vai e vem da filosofia como disciplina no currículo escolar acabou gerando uma instabilidade muito grande em sua estruturação teórica e profissional. O que melhor explica esse fenômeno são as oscilações decorrentes das disputas políticas existentes desde a sua aceitação no componente curricular. 
Isso demonstra com muita eloquência que existem interesses os mais variados por trás da organização do sistema de ensino. Como bem afirmou FREIRE (2011), a escola não é um local destituído de ação política, pelo contrária, ela respira política para sobreviver enquanto sistema formal de ensino. Não se pode desconsiderar o fator político e ideológico presente no processo de ensino aprendizagem sem incorrer no risco de tornar o ambiente escolar um reprodutor da ideologia hegemônica reacionária. Paulo Freire alerta para a importância de fortalecer a autonomia do estudante. Mas como será isso possível se o aluno só terá acesso a uma só visão de mundo, aquela que é hegemônica e controlada pelas classes dominadoras.

Recentemente foi criada uma lei que mostra bem esse fenômeno de intermitência das disciplinas de humanas do currículo obrigatório. O Projeto de Lei No 867 de 2015 que visa inserir o Programa Escola Sem Partido nos Parâmetros Curriculares Nacionais, no seu Artigo $2^{\circ}$ e parágrafo primeiro afirma que a neutralidade ideológica deve compor seu conjunto de princípios. Já no parágrafo sete do mesmo artigo o texto afirma ser direito dos pais que seus filhos tenham uma educação moral em consonância com suas convicções. E no Artigo $3^{\circ}$ é vedada a veiculação de conteúdos que conflitem com as convicções morais dos pais dos alunos. Dessa forma tem-se buscado o fortalecimento de uma ideologia e a fragilização de outras possibilidades de entendimento de mundo que não se coadunam com a ideologia hegemônica.

A ideologia hegemônica mesmo presente em várias instâncias da vida humana deixa lacunas por onde a contra hegemonia se infiltra. Essas brechas acabam sendo preenchidas e acomodando novas formas de entendimento. Essas novas ideias que compõem, mesmo que a contra gosto, a conjuntura ideológica hegemônica pode ganhar corpo de tal maneira que acabem sendo absorvidas como parte essencial da cultura hegemônica. Porém, não é sem resistência que elas se infiltram. O Projeto de Lei No 867 de 2015 é uma prova da existência de um aparelho contra hegemônico em operação no Brasil que força a entrada na estrutura ideológica hegemônica.

Conhecer melhor os conceitos de hegemonia e contra hegemonia pode trazer uma visão crítica desse embate que hora se apresenta no cenário educacional brasileiro. Entender os principais aspectos constitutivos, a natureza filosófica e as diretrizes de conservação e resistência da ideologia produz, com toda certeza, uma fundamentação para o entendimento crítico e autônomo da sociedade como um todo e da educação em particular.

Esse embate ideológico mascarado e falseado por quem deseja apresentar a realidade sob um filtro de harmonia social e solidariedade orgânica sempre, acaba sendo desmascarado e desvelado diante de ações reacionárias e afirmativas que tentam naturalizar e retirar das consciências incautas os verdadeiros fatores determinantes da vida como ela é. E entre esses 
fatores, como bem salientou Gramsci, está a educação que, como a religião, o folclore a educação e a filosofia é produto da ação política e ideológica duma sociedade determinada.

\section{CONSIDERAÇÕES FINAIS}

Esse trabalho contempla uma série de elementos que merecem discussão e debate, principalmente a ideia que trata das compreensões que existem sobre ideologia e seu uso deliberado crítico e acrítico. Além dessa temática, existe também a proposição que afirma ser a escola um ambiente neutro e de desnecessário embate político ideológico. O que não configura como realidade, pois mesmo o senso comum é considerado nesse trabalho uma visão de mundo montada historicamente.

No primeiro tópico foi colocado várias noções de verdade e como o tema é complexo do ponto de vista filosófico. Falou-se sobre os conceitos clássicos de verdade e sua importância para formalização do conceito de ideologia que, nesse trabalho, evoca alguns conceitos mais aceitos pela maioria, mas que propõe a se debruçar com maior força sobre o que se apresente em Gramsci.

No segundo tópico apresentado ficou claro as várias possibilidades existentes para o conceito de ideologia. Nesse tópico encontramos o conceito geral para ideologia e conceitos mais específicos para o termo, como o caso marxista que aceita a ideia de que ideologia é produto deliberado historicamente sob a orientação de uma classe hegemônica. Além disso é notório a presença da ideologia como mecanismo que orienta a formação cultural e cognitiva da sociedade, mas também, como elemento contra hegemônico capaz de corroborar na construção duma crítica contrária a configuração ideológica hegemônica.

Já no terceiro tópico foi apresentada importância de se compreender os conceitos de ideologia, hegemonia e contra hegemonia em Antônio Gramsci, para compreendermos melhor as disputas existentes na sociedade e como elas estão presentes em todo ambiente social que vivemos. Foi também nesse tópico explicitado o quanto se deve valorizar a aprendizagem significativa para alcançar qualquer alvo colocado diante da mira da educação. Todo tipo de aprendizado para surtir um mínimo de efeito positivo requer a associação daquilo que já existe na cultura do aluno, com o que se planeja no currículo da escola, que é político. Então, partir de uma base, mesmo que movediça, pois todo conhecimento é inacabado, é pedagogicamente aceitável e adequado quando se pretende construir um conhecimento mais sólido, significativo, autônomo e crítico. 
Diante de tudo que foi posto, acabo concluindo o quão importante é uma consciência autônoma que saiba conviver sem se deixar conduzir aleatoriamente por mãos invisíveis e bem intencionadas. Quando for necessário apontar um alvo para alguém, que usemos a ética pautada na alteridade e no respeito a autonomia do outro. Quando for necessária a obediência, que ela seja produto duma consciência livre, autônoma, clara, intencional e solidária.

Conhecer melhor os conceitos de hegemonia e contra hegemonia pode trazer uma visão crítica desse embate que hora se apresenta no cenário educacional brasileiro. Entender os principais aspectos constitutivos, a natureza filosófica e as diretrizes de conservação e resistência da ideologia produz, com toda certeza, uma fundamentação para o entendimento crítico e autônomo da sociedade como um todo e da educação em particular.

\section{REFERÊNCIAS}

ABBAGNANO, Nicola. Dicionário de Filosofia. São Paulo: Martins Fontes, 2007. Disponível em: <http://www.eduardoguerreirolosso.com/abbagnano-dicionario-de-filosofia.pdf>

BRASIL. Câmara dos Deputados. Projeto de Lei Complementar PLC 867/2015. Que dispõe sobre a inclusão nas diretrizes e bases da educação nacional o "Programa Escola Sem Partido". Disponível $<$ http:/ /www.camara.gov.br/proposicoesWeb/fichadetramitacao?idProposicao $=1050668>$. Acesso em: 08/08/2016.

Orientações Curriculares para o Ensino Médio / Ciências Humanas e suas Tecnologias. Volume 3. Brasília: Ministério da Educação, Secretaria de Educação Básica, 2008.

CHAUI, Marilena. O que é ideologia. São Paulo: Ed. Brasiliense, 2008.

COUTINHO, Carlos Nelson. Intervenções: o marxismo na batalha das ideias. São Paulo: Cortez, 2006.

LÖWY, Michel. Ideologia e Ciências Sociais. São Paulo: Ed. Cortez, 2015.

FREIRE, Paulo. Pedagogia da autonomia: saberes necessários à prática educativa. 30. ed. Rio de Janeiro: Paz e Terra, 2002. 148 p. (Coleção leitura)

PELIZZARI, Adriana. et al. Teoria da Aprendizagem Significativa. Disponível em: <http://www.moodle2.univasf.edu.br/posgraduacaoead/pluginfile.php/6489/mod_resource/co ntent $/ 2 /$ teoria_da_aprendizagem $\% 20$ significativa.pdf $>$

SAVIANI, Demerval. Escola e Democracia. Edição Comemorativa. Campinas: Autores Associados, 2008. 112p (Coleção Educação Contemporânea). 